\title{
Genome sequencing, assembly, and annotation of the self-flocculating microalga Scenedesmus obliquus AS-6-11
}

\author{
Bai-Ling Chen ${ }^{1}$, Wuttichai Mhuantong ${ }^{2}$, Shih-Hsin $\mathrm{Ho}^{3}$, Jo-Shu Chang ${ }^{4,5,6}$, Xin-Qing Zhao ${ }^{1 *}$ (D) and Feng-Wu Bai ${ }^{1}$
}

\begin{abstract}
Background: Scenedesmus obliquus belongs to green microalgae and is widely used in aquaculture as feed, which is also explored for lipid production and bioremediation. However, genomic studies of this microalga have been very limited. Cell self-flocculation of microalgal cells can be used as a simple and economic method for harvesting biomass, and it is of great importance to perform genome-scale studies for the self-flocculating S. obliquus strains to promote their biotechnological applications.

Results: We employed the Pacific Biosciences sequencing platform for sequencing the genome of the selfflocculating microalga S. obliquus AS-6-11, and used the MECAT software for de novo genome assembly. The estimated genome size of S. obliquus AS-6-11 is $172.3 \mathrm{Mbp}$ with an N50 of 94,410 bp, and 31,964 protein-coding genes were identified. Gene Ontology (GO) and KEGG pathway analyses revealed 65 GO terms and 428 biosynthetic pathways. Comparing to the genome sequences of the well-studied green microalgae Chlamydomonas reinhardtii, Chlorella variabilis, Volvox carteri and Micractinium conductrix, the genome of S. obliquus AS-6-11 encodes more unique proteins, including one gene that encodes D-mannose binding lectin. Genes encoding the glycosylphosphatidylinositol (GPI)-anchored cell wall proteins, and proteins with fasciclin domains that are commonly found in cell wall proteins might be responsible for the self-flocculating phenotype, and were analyzed in detail. Four genes encoding both GPI-anchored cell wall proteins and fasciclin domain proteins are the most interesting targets for further studies.

Conclusions: The genome sequence of the self-flocculating microalgal S. obliquus AS-6-11 was annotated and analyzed. To our best knowledge, this is the first report on the in-depth annotation of the S. obliquus genome, and the results will facilitate functional genomic studies and metabolic engineering of this important microalga. The comparative genomic analysis here also provides new insights into the evolution of green microalgae. Furthermore, identification of the potential genes encoding self-flocculating proteins will benefit studies on the molecular mechanism underlying this phenotype for its better control and biotechnological applications as well.
\end{abstract}

Keywords: Green microalgae, Scenedesmus obliquus, Genome assembly and annotation, Comparative genomics, Cell self-flocculation

\footnotetext{
* Correspondence: xqzhao@sjtu.edu.cn

${ }^{1}$ State Key Laboratory of Microbial Metabolism, Joint International Research Laboratory of Metabolic \& Developmental Sciences, School of Life Sciences and Biotechnology, Shanghai Jiao Tong University, Shanghai 200240, China Full list of author information is available at the end of the article
}

(c) The Author(s). 2020 Open Access This article is licensed under a Creative Commons Attribution 4.0 International License, which permits use, sharing, adaptation, distribution and reproduction in any medium or format, as long as you give appropriate credit to the original author(s) and the source, provide a link to the Creative Commons licence, and indicate if changes were made. The images or other third party material in this article are included in the article's Creative Commons licence, unless indicated otherwise in a credit line to the material. If material is not included in the article's Creative Commons licence and your intended use is not permitted by statutory regulation or exceeds the permitted use, you will need to obtain permission directly from the copyright holder. To view a copy of this licence, visit http://creativecommons.org/licenses/by/4.0/ The Creative Commons Public Domain Dedication waiver (http://creativecommons.org/publicdomain/zero/1.0/) applies to the data made available in this article, unless otherwise stated in a credit line to the data. 


\section{Background}

Microalgae are widely studied for producing biofuels and mitigating greenhouse gas emissions [1]. In addition, microalgae are also producers of various high-value biochemicals, such as lipids, proteins, polysaccharides, pigments, vitamins, and antioxidants [2]. For economic bioproduction by microalgae, robust strains and optimized processes are both essential [3]. Genome-scale studies of microalgae can provide in-depth information on intracellular metabolism from a global prospect [46], and benefit the development of robust microalgal strains and efficient processes. Therefore, studies on genome sequencing and annotation of microalgae have received increasing attention.

Due to small cell size, negative surface charge and low biomass concentration achieved during photosynthetic autotrophic culture, harvesting microalgae biomass from a large volume of culture medium is a great challenge for their biorefinery $[7,8]$. Among various technologies developed for microalgal biomass recovery, gravity sedimentation facilitated by the flocculation of microalgal cells is more economically competitive [8]. On the other hand, some microalgal strains can flocculate or aggregate spontaneously [9-11]. The self-flocculation of microalgal cells enables their harvest without the addition of exogenous flocculants, and biomass harvesting based on the selfflocculation of microalgal cells is more environmentally friendly compared to the flocculation of microalgal cells through physical and chemical methods, or induced by infochemicals from predators $[8,12]$.

Despite the progress in using cell flocculation of microalgae for biomass recovery, in-depth studies on mechanisms of microalgal cell flocculation are still lacking. So far, microalgal cell wall polysaccharide and other extracellular polymeric substances (EPS) containing sugars and proteins have been identified as flocculating agents [10, $11,13]$, but genes involved in the process remain unexplored. Identification of genes involved in microalgal cell self-flocculation is of importance to develop robust strains with controlled flocculation phenotype for microalgal biorefinery, which can be enabled by the advancement of genetic engineering of microalgae [14].

Scenedesmus belongs to green microalgae and is useful for lipid and pigment production, wastewater treatment, heavy metal removal and $\mathrm{CO}_{2}$ fixation [14-18]. The selfflocculating microalga $S$. obliquus AS-6-1 showing great advantages in microalgal cell harvest and heavy metals adsorption was reported previously $[10,16]$. However, genes encoding key protein(s) for the synthesis of flocculating agents in S. obliquus are still not clear. To date, the genome sequences of four Scenedesmus strains are available (NCBI BioProjects PRJNA498405, PRJNA394817, PRJNA394817 and PRJNA428298), but none of them have been annotated adequately. Three of these genomes lack annotation information, and the annotation of the remaining strain Scenedesmus sp. ARA is incomplete due to the large contig numbers of 4727 and a low N50 value of 37,561. Additionally, the three Scenedesmus genomes were sequenced by the second-generation sequencing (SGS) technology that might cause bias annotation due to shorter read lengths compared with Pacific Biosciences (Pacbio) sequencing technology [19].

In this study, we sequenced the self-flocculating $S$. obliquus AS-6-11 genome using the Pacbio technology and reported its genome assembly and annotation. We explored the metabolic potential of this microalga, and performed comparative genome analyses with the other four annotated microalgal genomes. We also comprehensively analyzed the cell wall proteins of $S$. obliquus AS-6-11 that might act as the flocculating agents for the self-flocculating phenotype. The knowledge obtained in this work can not only benefit understanding and control of the self-flocculation of microalgal cells, but will also provide insights for further genome-scale studies of S. obliquus and other related microalgae to explore their biotechnological potentials.

\section{Results}

\section{Morphological features and genome assembly}

Cell self-flocculation of S. obliquus AS-6-11 was observed by SEM analysis. The microalgal cells are round and form aggregates through cell-cell contacts (Fig. 1), which is different from the other reported Scenedesmus strains that are in spindle shape [12].

The estimated genome size of S. obliquus AS-6-11 is 172.3 Mbp with 2772 contigs, and the N50 contig size is 94.4 kbp using MECAT for the genome assembly (Additional file 1: Table S1; NCBI BioProject ID: PRJNA593662). Results using the MECAT software showed a better assembly ability than that of SMRT

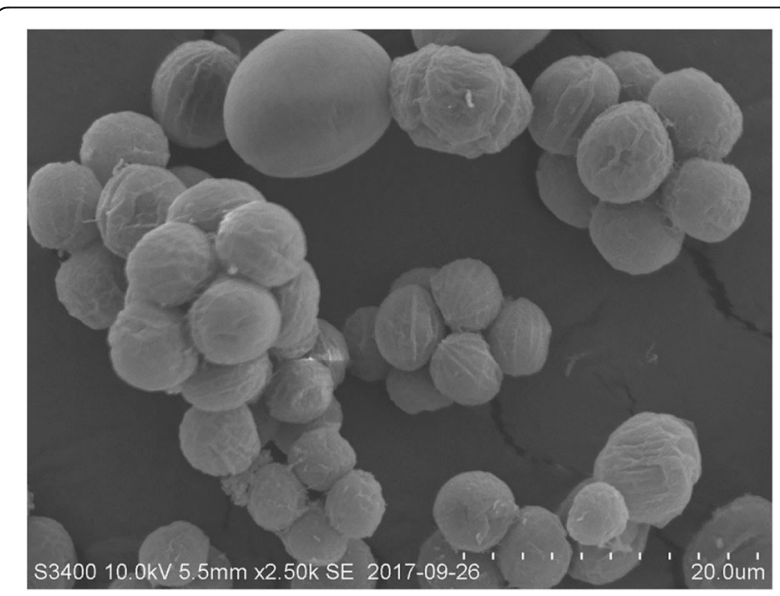

Fig. 1 Morphological observation of self-flocculation S. obliquus AS6-11 by SEM 
Portal in S. obliquus AS-6-11, in which the contig numbers are $58.1 \%$ less, and the N50 value is 1.5 -fold higher (Additional file 1: Table S1). The genome sizes of the released Scenedesmus strains [20-24] range from 23.4 to 208.0 Mbp (Table 1). Among the available results, the N50 contig sizes of $S$. obliquus AS-6-11 reported in this study and S. obliquus strain DOE0152z using Pacbio technology are significantly higher than the other Scenedesmus strains using SGS (Table 1). The N50 contig size of S. obliquus AS-6-11 is 1.2-fold and 10.7-fold higher than Scenedesmus sp. MC-1 and S. quadricauda LWG 002611, respectively. Besides, the GC content of Scenedesmus strains ranges from 52.0 to $63.2 \%$, and S. obliquus AS-6-11 has the lowest GC content (Table 1). Benchmarking Universal Single-Copy Orthologs (BUSCO) analysis showed that the assembly of S. obliquus AS-6-11 is $87.1 \%$ complete with 2168 BUSCO groups (Additional file 2).

\section{Genome annotations}

A total of 31,964 protein-coding genes were predicted in the S. obliquus AS-6-11 genome (Table 2). The predicted gene number of $S$. obliquus AS-6-11 genome is dramatically higher than the other Scenedesmus strains (Table 1). According to the Non-redundant protein (NR), SWISS-PROT, and Pfam protein families databases, 19,847, 13,099, and 13,612 proteins were annotated, respectively (Table 2). The protein number annotated based on the NR database is the largest, which is 1.52-fold higher than that obtained based on the SWISS-PROT database. Besides, 65 GO terms and 428 pathways were predicted by Gene Ontology (GO) and Kyoto Encyclopedia of Genes and Genomes (KEGG) databases in S. obliquus AS-6-11, respectively.

The top 20 GO terms and KEGG pathways enriched in gene function annotation of the S. obliquus AS-6-11 genome were illustrated in Fig. 2. The top 20 GO terms are mainly located in biological process (10) and cellular component (8), in which the cell, cell part, and organelle are the top three GO terms (Fig. 2a). The top 20 KEGG pathways are mainly related to genetic information
Table 2 Summary of the S. obliquus AS-6-11 genome annotation

\begin{tabular}{ll}
\hline Protein database & Annotated protein numbers \\
\hline NR & 19,847 \\
SWISS-PROT & 13,099 \\
Pfam & 13,612 \\
GO & 11,734 \\
KEGG & 3302 \\
\hline
\end{tabular}

processing (14), in which chromosome and associated proteins, membrane trafficking, and spliceosome are the top three KEGG pathways (Fig. 2b).

\section{Comparative genomic analysis based on KEGG pathways}

A total of 428 pathways were annotated in the S. obliquus AS-6-11 genome. In terms of lipid metabolism, the fewest genes (171) were annotated in S. obliquus AS-611, especially in glycerolipid metabolism, glycerophospholipid metabolism and arachidonic acid metabolism (Table 3). However, more genes related to fatty acid biosynthesis and elongation were identified in $S$. obliquus AS-6-11 than that in C. reinhardtii and V. carteri (Table $3)$. Moreover, genes in the carotenoid biosynthesis in $S$. obliquus AS-6-11 are the fewest.

\section{Comparative genomic analysis of orthologous gene clusters}

Comparing with the other four species, S. obliquus AS6-11 has 15,879 gene clusters with 14,576 orthologous clusters and 1303 single-copy gene clusters (Fig. 3). There are 3357 overlapping orthologous gene clusters among the five microalgae. S. obliquus AS-6-11 has the most gene clusters and singletons (defined as the singleton genes for which no orthologs could be found in any of the other species [25]), and the number (8751) is 1.26-fold, 3.71-fold, 5.34-fold and 1.67-fold higher than that in C. reinhardtii, C. variabilis, $M$. conductrix and $V$. carteri, respectively (Fig. 3). Comparative orthologous gene cluster analysis also showed that the phylogenetic

Table 1 Genomic information of the reported Scenedesmus strains ${ }^{a}$

\begin{tabular}{|c|c|c|c|c|c|c|c|}
\hline Strains & $\begin{array}{l}\text { Genome size } \\
\text { (Mbp) }\end{array}$ & GC content $(\%)$ & $\begin{array}{l}\text { Contig } \\
\text { numbers }\end{array}$ & N50 value (bp) & $\begin{array}{l}\text { Sequencing } \\
\text { technology }\end{array}$ & $\begin{array}{l}\text { Gene } \\
\text { number }\end{array}$ & $\begin{array}{l}\text { Reference/ } \\
\text { BioProjects }\end{array}$ \\
\hline Scenedesmus sp. ARA & 93.2 & 56.8 & 4727 & 37,561 & Illumina HiSeq & - & {$[20]$} \\
\hline Scenedesmus sp. MC-1 & 38.2 & 61.4 & - & 42,815 & Illumina HiSeq 2000 & 8652 & {$[21]$} \\
\hline S. vacuolatus & 23.4 & 53.6 & 20,139 & 1571 & 454 & 20,139 & PRJNA498405 \\
\hline S. quadricauda isolate LWG 002611 & 65.4 & 63.2 & 13,425 & 8094 & Ion Proton & 13,514 & {$[22]$} \\
\hline Tetradesmus obliquus UTEX393 & 108.7 & 56.8 & 9191 & - & Illumina Hiseq2000 & - & {$[23]$} \\
\hline S. obliquus strain DOE0152z & 208.0 & 56.7 & 2705 & 155,544 & PacBio & - & {$[24]$} \\
\hline S. obliquus AS-6-11 & 172.3 & 52.0 & 2772 & 94,410 & PacBio & 31,964 & This study \\
\hline
\end{tabular}

a means information not available 
a

GO terms

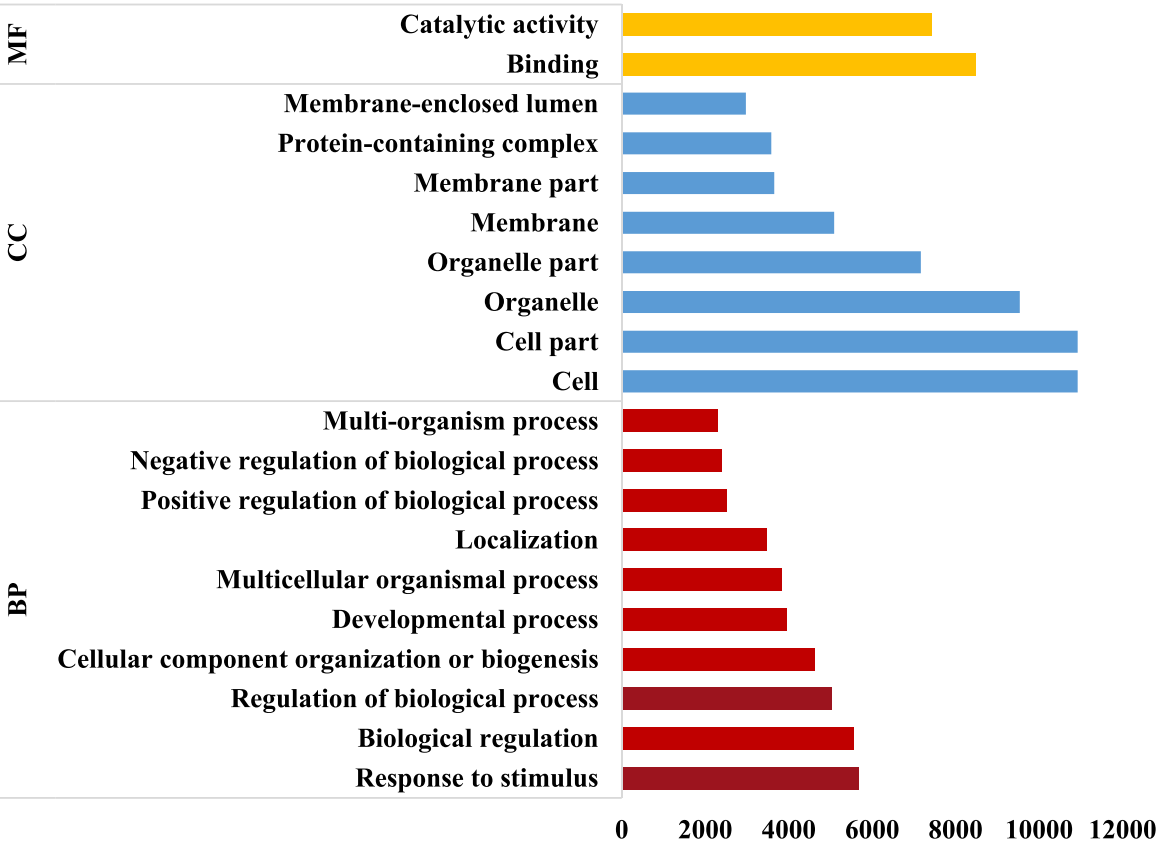

b

\section{KEGG Pathways}

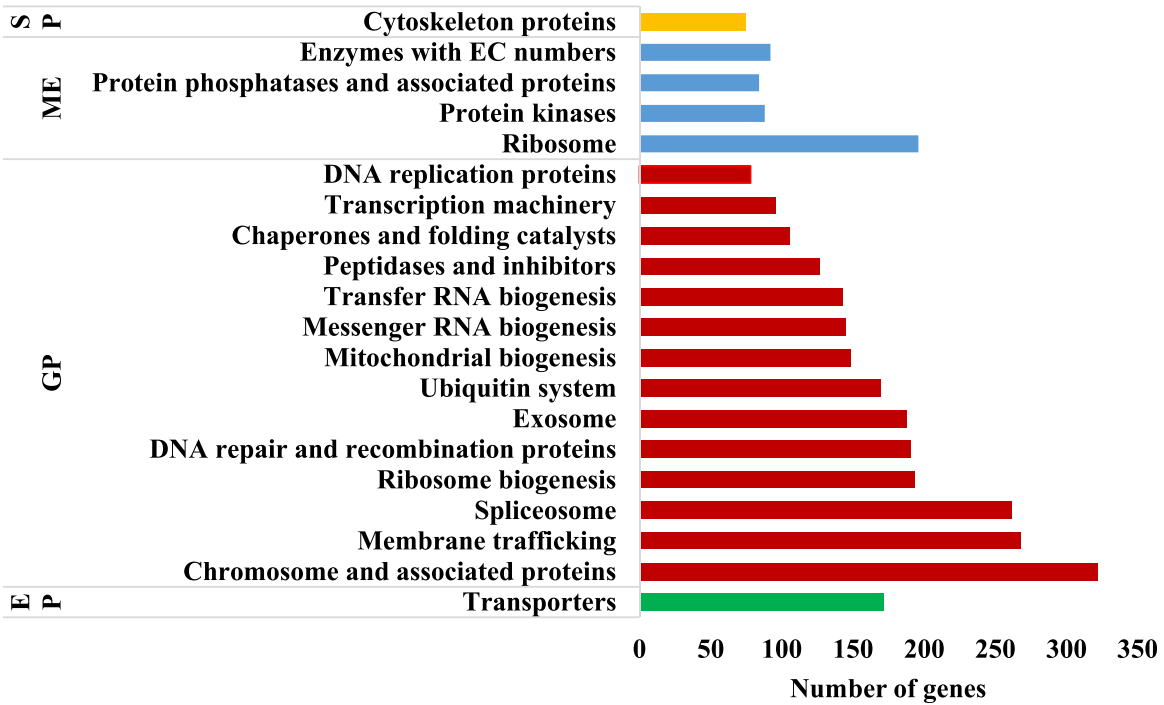

Fig. 2 Gene functional annotation analysis of S. obliquus AS-6-11 genome. a The top 20 of GO categories enriched by gene functional annotation analysis of S. obliquus AS-6-11 genome; $\mathbf{b}$ The top 20 of KEGG pathways enriched by gene functional annotation analysis of S. obliquus AS-6-11 genome. BP: Biological process; CC: Cellular component; EP: Environmental information processing; GP: Genetic information processing; ME:

Metabolism; MF: Molecular function; SP: Signaling and cellular processes

proximity of $S$. obliquus AS-6-11 is very similar to that of the other four microalgae (Additional file 3: Fig. S1).

Comparative genomic analysis based on gene families A total of 3608 gene families were identified in S. obliquus AS-6-11, in which 136 unique gene families existed (Fig. 4). Both the total and unique gene families in $S$. obliquus AS-6-11 are more abundant than that in the other four microalgae (Fig. 4). The number of the unique gene families in S. obliquus AS-6-11 is 0.86, 1.19, 1.31 and 1.39-fold larger than C. reinhardtii, C. variabilis, $M$. conductrix and $V$. carteri, respectively (Fig. 4). In the S. obliquus AS-6-11 genome, the unique gene families include membrane protein (PF10160), red 
Table 3 Analysis of gene numbers of the key metabolic pathways among the five microalgae

\begin{tabular}{|c|c|c|c|c|c|}
\hline KEGG pathways & C. reinhardtii & C. variabilis & M. conductrix & V. carteri & S. obliquus AS-6-11 \\
\hline \multicolumn{6}{|l|}{ Lipid metabolism } \\
\hline Fatty acid biosynthesis & 23 & 26 & 27 & 24 & 26 \\
\hline Fatty acid elongation & 7 & 8 & 10 & 8 & 8 \\
\hline Fatty acid degradation & 16 & 21 & 15 & 18 & 18 \\
\hline Steroid biosynthesis & 9 & 12 & 14 & 9 & 10 \\
\hline Steroid hormone biosynthesis & 5 & 4 & 4 & 4 & 3 \\
\hline Glycerolipid metabolism & 28 & 28 & 30 & 28 & 21 \\
\hline Glycerophospholipid metabolism & 35 & 37 & 35 & 32 & 30 \\
\hline Ether lipid metabolism & 5 & 9 & 7 & 6 & 5 \\
\hline Sphingolipid metabolism & 18 & 16 & 14 & 16 & 17 \\
\hline Arachidonic acid metabolism & 14 & 13 & 13 & 10 & 7 \\
\hline Alpha-linolenic acid metabolism & 10 & 13 & 14 & 11 & 9 \\
\hline Biosynthesis of unsaturated fatty acids & 10 & 15 & 14 & 12 & 11 \\
\hline \multicolumn{6}{|l|}{ Metabolism of terpenoids and polyketides } \\
\hline Carotenoid biosynthesis & 12 & 11 & 14 & 12 & 10 \\
\hline
\end{tabular}

chlorophyll catabolite reductase (RCC reductase, PF06405), D-mannose binding lectin (PF01453), lipase maturation factor (PF06762), lipid-A-disaccharide synthetase (PF02684), thioesterase-like superfamily (PF13279) and so on. In addition, S. obliquus AS-6-11 and $M$. conductrix have the most common gene families (Fig. 4).

\section{Analysis of the genome features related to cell self- flocculation}

Cell self-flocculation of budding yeast Saccharomyces cerevisiae has been well-studied. The flocculation proteins, for example, Flo1p, Flo5p, Flo9p, and Flo10p, are cell wall proteins (CWPs) and also called lectin [26, 27]. GPI-anchor was reported as the common element in cell adhesion proteins and the GPI-anchored adhesins in yeast species of Candida albicans and S. cerevisiae are the well-known fungal adhesions [28]. In S. obliquus AS6-11, a total of 432 GPI-anchored CWPs are identified. Analysis of the top 10 GPI-anchored CWPs indicated that seven of them has the transmembrane region, and eight of them had the signal peptides (Table 4). The isoelectric point (pI) and molecular weight $(\mathrm{Mw})$ of the GPI-anchored CWPs vary from 4.95 to 9.58 and 6.10 $\mathrm{KDa}$ to $78.84 \mathrm{KDa}$, respectively (Table 4 ).

Fasciclin (PF02469) is an extracellular domain (http:// pfam.xfam.org/family/PF02469) that belongs to the ancient cell adhesion domain that is common to plants and animals. So far, fasciclin domain proteins have not been analyzed in microalgae. In the S. obliquus AS-6-11 genome, a total of 33 fasciclin domain proteins are identified, which are divided into three groups (Fig. 5a). Three main motifs are randomly distributed across the fasciclin domain proteins (Fig. 5b). The predicted pI values and $\mathrm{Mw}$ greatly differ among the fasciclin domain proteins (Additional file 4: Table S2). The subcellular localization prediction of fasciclin domain proteins indicated that most proteins have cytoplasmic (cyto) sites, and 15 of them have secreted (extr) sites (Additional file 4: Table S2). Further analysis of these 15 fasciclin domain proteins containing extr sites showed that six proteins are homologous to the reported fasciclin proteins of Monoraphidium neglectum (64.84\%), Aquabacterium sp. (61.36\%), Scenedesmus sp. Ki4 (48.09\%), Pelomonas puraquae (46.94\%) (Table 5). Additionally, two of the predicted proteins are annotated into the extracellular region part according to the $\mathrm{GO}$ database.

Combining analysis of GPI-anchored CWPs and fasciclin domain proteins, four fasciclin domain proteins were found to distribute in GPI-anchored CWPs (Fig. 6a; Additional file 5), in which one has two FAS1 domains (four repeated domains in the fasciclin I family of proteins), two have transmembrane regions, and one has signal peptide (Fig. 6a). Comparative genomic analysis of S. obliquus AS-6-11 and the other four microalgae species (C. reinhardtii, C. variabilis, $M$. conductrix and $V$. carteri) revealed no similar proteins to the four fasciclin domain proteins. We also performed comparative transcriptome analysis of S. obliquus AS-6-11 and the nonflocculating S. obliquus FSP-3, and the results showed that the four fasciclin domain protein-encoding genes (Fig. 6a) had transcription level in S. obliquus AS-6-11, but the transcription of these genes cannot be detected in S. obliquus FSP-3 (Additional file 6: Table S3).

The unique gene family D-mannose binding lectin was also analyzed (Additional file 5). One gene belongs to 


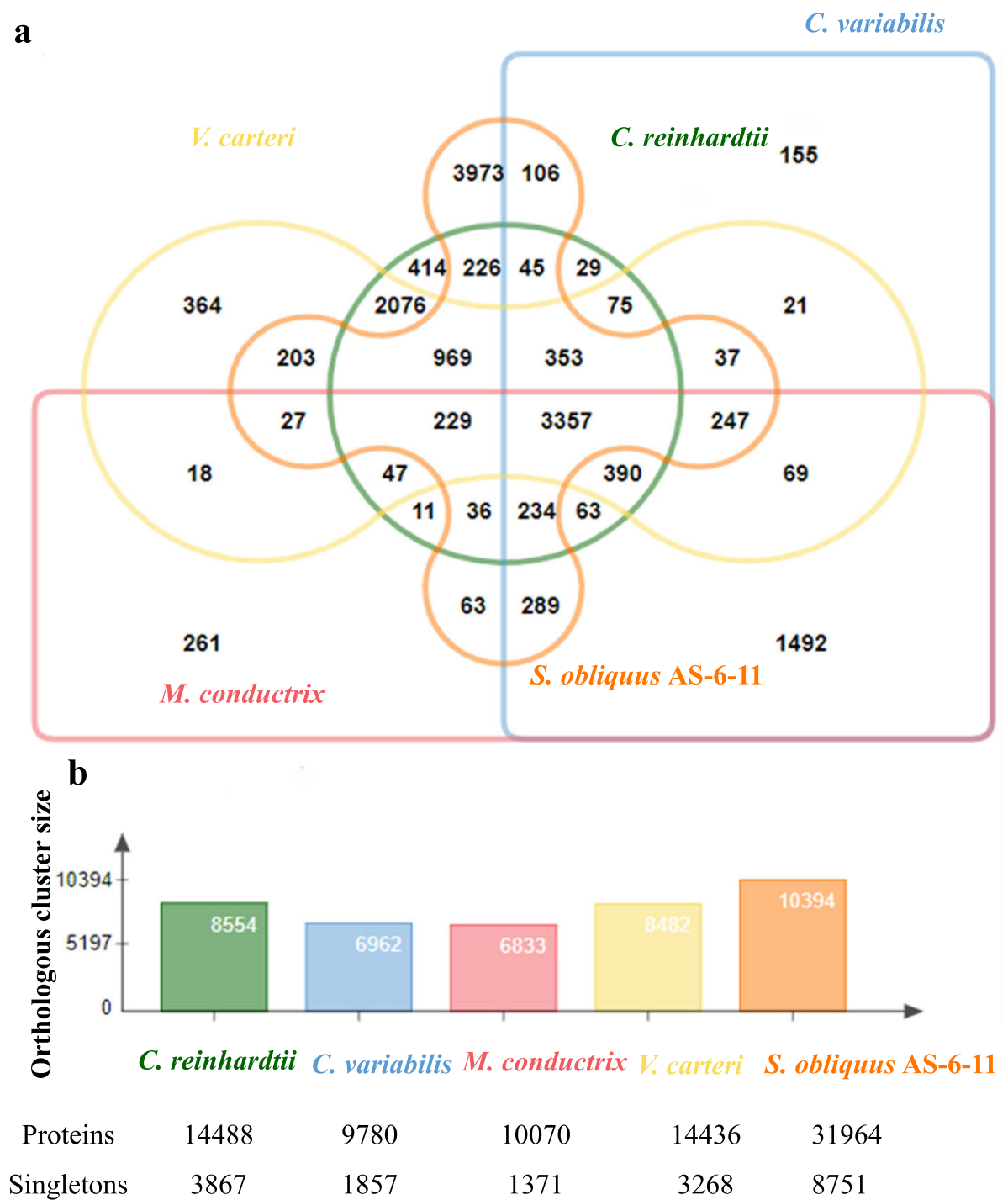

Fig. 3 The orthologous gene clusters in the five microalgae. a. The shared and different orthologous gene clusters; $b$. The size of each orthologous gene clusters

this unique gene family was identified, and the encoded protein has two conserved domains: CAP (cysteine-rich secretory proteins) domain and B_lectin (D-mannose binding lectin) domain. The putative D-mannose binding lectin of S. obliquus AS-6-11 is homologous to a secreted glycoprotein Pry1p of S. cerevisiae YJM693 (SGD ID: S000003615), and the identity is $58 \%$ (Fig. 6b). The similarity between Pry1p and D-mannose binding lectin attributes to the same CAP domain (Fig. 6b).

\section{Discussion}

Genome feature of S. obliquus AS-6-11

We report here the genome sequence and annotation of S. obliquus AS-6-11, which is the first sequenced selfflocculating microalgal genome, and is also so far the most comprehensively annotated genome among the available $S$. obliquus genome information. The much larger gene numbers of S. obliquus AS-6-11 (Table 1) suggested its unique feature. Considering the relative completeness of S. obliquus AS-6-11 genome and the lack of S. obliquus genome annotation, S. obliquus AS-611 may serve as a model alga for supplying reference genome annotation and investigating the gene function, evolution, and biotechnology application of S. obliquus strains.

We obtained a larger contig N50 size of S. obliquus AS-6-11 genome than that of Scenedesmus sp. MCand S. quadricauda, which may attribute to Pacbio sequencing technology and the assembly tool MECAT [29]. The MECAT software showed higher computing 


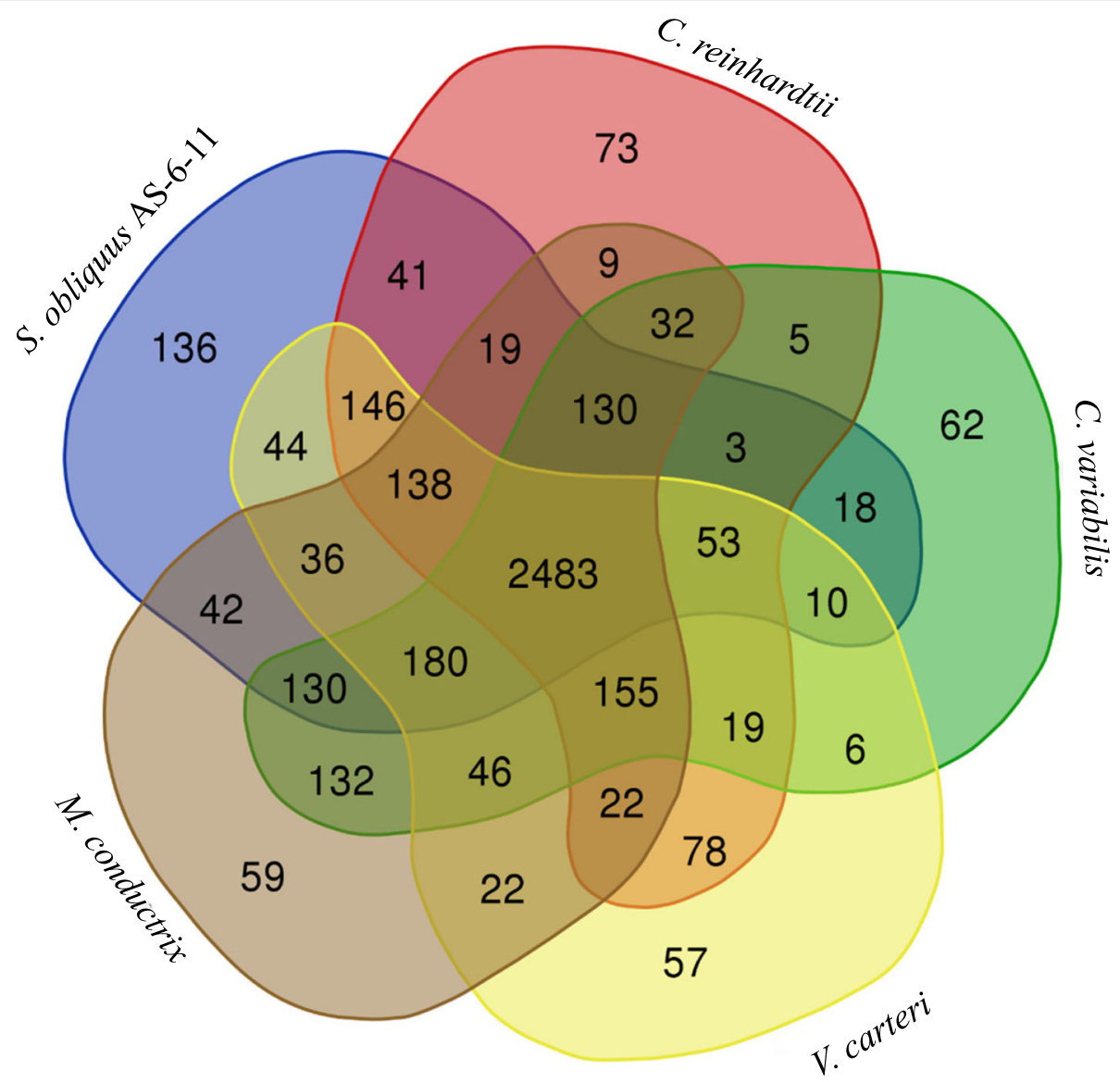

Fig. 4 Venn diagram of shared/unique gene families among the five microalgae

efficiency with comparable or improved genome results than other current tools for de novo assembly of large genomes [29], and this study is the first application of this tool in the genome assembly of microalgae.
Comparative analysis of S. obliquus AS-6-11 genome with the other microalgae

Due to the lack of genome annotations of Scenedesmus strains, we compared the S. obliquus AS-6-11 genome with four represented green microalgae (Fig. 3; Fig. 4;

Table 4 Analysis of the top 10 GPI-anchored CWPs with signal peptides ${ }^{a}$

\begin{tabular}{llllll}
\hline Protein name & GPI probability (\%) & pl & Mw $(\mathbf{K D a})$ & SMART analysis & Subcellular localization sites \\
\hline Sco00011036 & 99.82 & 6.75 & 7.13 & TMR & vacu: 8, chlo: 2, plas: 2, extr: 1, golg: 1 \\
Sco00023226 & 99.73 & 5.38 & 30.84 & TMR & vacu: 8, plas: 4, extr: 2 \\
Sco00002357 & 99.65 & 6.36 & 9.68 & TMR & extr: 7, E.R: 3.5, E.R._plas: 3, mito: 2, plas: 1.5 \\
Sco00003994 & 99.51 & 4.95 & 21.28 & - & extr: 12, mito: 1, E.R:: 1 \\
Sco00022819 & 99.47 & 8.59 & 29.73 & TMR & extr: 11, mito: 2, vacu: 1 \\
Sco00000470 & 99.41 & 9.58 & 14.83 & TMR & vacu: 7, plas: 3, extr: 2, E.R:: 1, golg: 1 \\
Sco00000669 & 99.33 & 8.48 & 6.10 & - & extr: 12, mito: 1, plas: 1 \\
Sco00004618 & 99.02 & 7.51 & 15.28 & TMR & extr: 9, vacu: 3, chlo: 2 \\
Sco00003952 & 98.73 & 7.51 & 78.84 & TMR & plas: 11, vacu: 2, E.R.: 1 \\
Sco00008125 & 98.71 & 5.22 & 8.87 & - & plas: 11, extr: 11, vacu: 2, nucl: 1, cyto: 1, E.R.: 1
\end{tabular}

${ }^{a}$ chlo chloroplast, cyto cytoplasmic, E.R. endoplasmic reticulum, extr secreted, golg golgi apparatus, mito mitochondrial matrix, plas membrane protein, TMR Transmembrane region, vacu vacuolar. '-' represented no information available 
$\mathbf{a}$

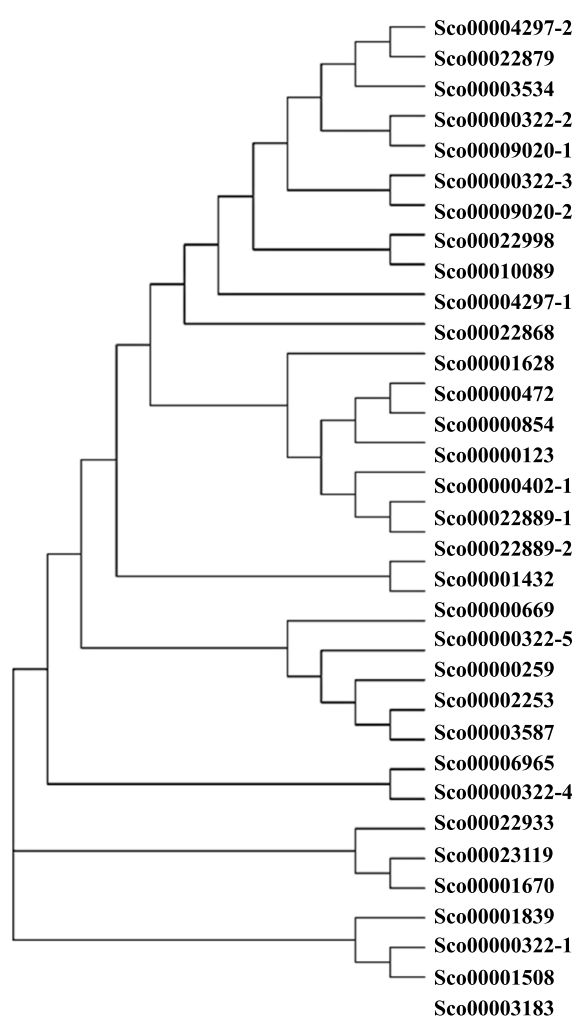

b

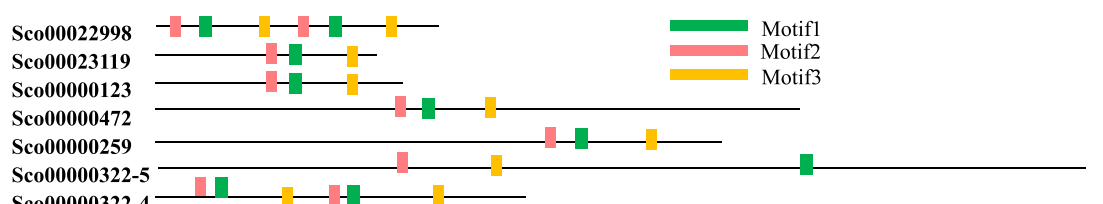

Sco00000322-5

Sco00000322-3 —-

Sco00000322-1

Sco00000322-2

Sco00000402-1

Sco0000085 - -

Sco00001670 —

Sco00001432 -

Sco00001508 —_-

Sco00001839 - -

Sco00001628

Sco00002253 -

$S \operatorname{Sco0000253} \longrightarrow$
Sco00003534

Sco00003183 -

Sco00003587

Sco00004297-1

Sco00004297-2

Sco00009020-1

Sco00009020-2- -

Sco00006965

Sco00010089 -

Sco00022889-1 -

Sco00022889-2-

Sco00022879

Sco00028

Sco00022868

Sco00022933

Sco00000669

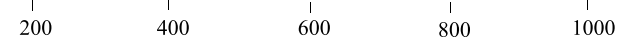

Fig. 5 The phylogenetic tree (a) and conserved motifs (b) of the fasciclin domain proteins in S. obliquus AS-6-11 
Table 5 Analysis of predicted extracellular secreted fasciclin domain proteins in S. obliquus AS-6-11 ${ }^{\text {a }}$

\begin{tabular}{|c|c|c|c|c|c|}
\hline Protein name & pl & Mw (KDa) & Signal peptide & The most similar homologous protein and the source organism & $\begin{array}{l}\text { Identity to the most } \\
\text { similar sequence }\end{array}$ \\
\hline Sco00000123 & 7.5 & 32.5 & - & hypothetical protein MNEG_1104 [Monoraphidium neglectum] & $63.00 \%$ \\
\hline Sco00000322-1 & 9.2 & 43.4 & 1 & hypothetical protein A109_09854 [Exophiala aquamarina CBS 119918] & $40.00 \%$ \\
\hline Sco00000322-2 & 8.8 & 35.1 & 1 & fasciclin domain-containing protein [Aquabacterium sp.] & $61.36 \%$ \\
\hline Sco00000402-1 & 8.9 & 23.4 & 1 & hypothetical protein D109_43p180 [Mitosporidium daphniae] & $38.78 \%$ \\
\hline Sco00001432 & 7.7 & 44.1 & 1 & Nex18 symbiotically induced [Micractinium conductrix] & $52.08 \%$ \\
\hline Sco00002253 & 7.1 & 80.0 & - & hypothetical protein MNEG_2497 [Monoraphidium neglectum] & $46.00 \%$ \\
\hline Sco00003534 & 4.2 & 29.9 & 1 & astaxanthin binding fasciclin family protein [Scenedesmus sp. Ki4] & $48.09 \%$ \\
\hline Sco00003587 & 7.6 & 84.4 & 1 & - & \\
\hline Sco00004297 & 6.3 & 16.4 & - & hypothetical protein Rsub_06992 [Raphidocelis subcapitata] & $61.54 \%$ \\
\hline Sco00009020 & 8.9 & 18.3 & - & fasciclin domain-containing protein [Aquabacterium sp.] & $61.36 \%$ \\
\hline Sco00022889-1 & 8.9 & 33.8 & 1 & fasciclin-like protein [Chlamydomonas reinhardti] & $38.75 \%$ \\
\hline Sco00022889-2 & 7.7 & 26.7 & 1 & fasciclin [Pelomonas puraquae] & $46.94 \%$ \\
\hline Sco00022879 & 5.2 & 12.2 & - & beta-lg-H3/fasciclin [Monoraphidium neglectum] & $64.84 \%$ \\
\hline Sco00000669 & 4.9 & 14.5 & - & fasciclin domain-containing protein [Marinobacter] & $53.85 \%$ \\
\hline
\end{tabular}

${ }^{\text {a}}$ The protein-coding genes that encode GPI-anchored CWPs were shown in bold font; '-' represented no information available

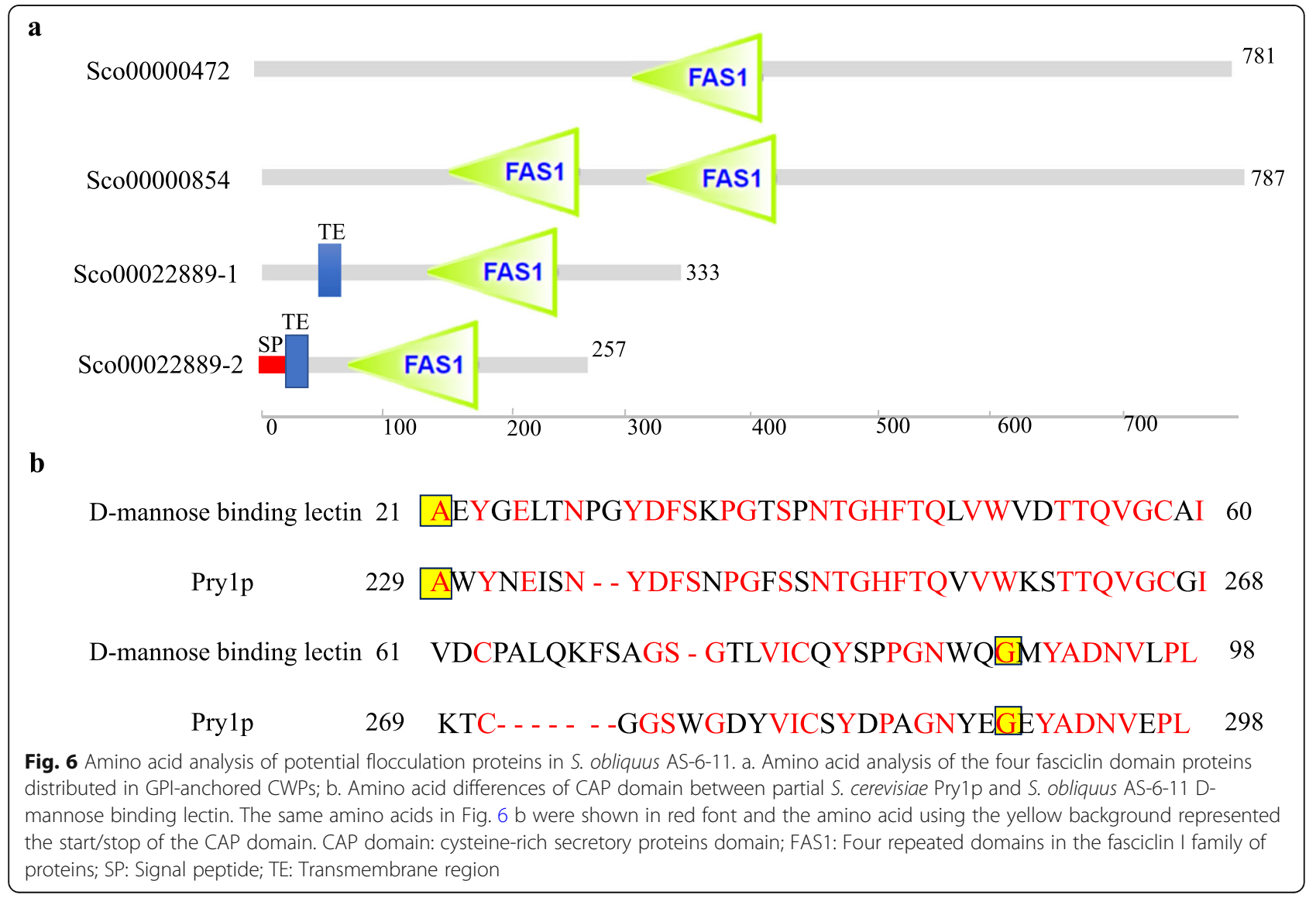


Table 3). S. obliquus AS-6-11 has more singletons, unique gene families as well as additional KEGG pathways than the other four microalgae, revealing its special evolutionary status, genomic complexity, and metabolic characteristics. Comparative genomics analysis of orthologous clusters among multiple species is important for identifying the overlap among orthologous clusters that helps to elucidate the evolution and function of proteins [25]. The similar phylogenetic proximity of S. obliquus AS-6-11 to the four green microalgae further supports that this species locates in the intermediate stage of green algae evolution [30].

Due to the potential applications of Scenedesmus strains in wastewater treatment and lipid production [31, 32], their lipid metabolism needs to be well-studied. S. obliquus AS-6-11 has fewer genes of lipid metabolism compared to S. quadricauda LWG002611 and the other four green microalgae, suggesting the difference of lipid biosynthesis or genome integrity among the strains. For example, the fewer genes of arachidonic acid metabolism in S. obliquus AS-6-11 may attribute to multiple genes encoding one enzyme in other microalgae (Table 3). Key enzymes involved in triacylglycerol (TAG) biosynthesis pathways and carbon fixation were identified based on the genome sequence of S. quadricauda LWG002611, providing targets for genetic and metabolic engineering to improve biofuel production and reconstruct the metabolic pathways of this strain [22]. In the previous work, overexpression of type 2 diacylglycerol acyltransferase gene (DGTT1) of C. reinhardtii in S. obliquus CPC2 enhanced its lipid content by nearly two-fold [33]. Overexpression of acetyl-CoA carboxylase gene in Scenedesmus sp. MC-1 increased its intracellular lipid by $28.6 \%$, indicating its importance in the lipid metabolism of Scenedesmus [21]. However, the endogenous genes involved in lipid biosynthesis in S. obliquus has not been investigated. The identified lipid biosynthetic genes in this work will facilitate improving lipid production in $S$. obliquus.

On the other hand, Scenedesmus can produce important pigments carotenoids as valuable products, and overexpression of synthetic phytoene synthase gene (PSY) in Scenedesmus sp. CPC2 increased $\beta$-carotene production to $30 \mathrm{mg} \mathrm{g}^{-1}$-cell [34]. So far no studies have been focused on the innate carotenoid biosynthetic genes in $S$. obliquus. Further investigation of the functional genome of Scenedesmus will benefit the metabolic engineering of this important microalga for carotenoids production.

\section{Potential flocculation proteins in S. obliquus AS-6-11}

Although bioflocculation has been widely accepted as a promising way to harvest microalgal biomass, studies on cell self-flocculation of microalgae are still very limited. In the previous study, cell wall polysaccharides were revealed to act as flocculating agents in S. obliquus AS-6-1 [10]. In the recent study, we found that protease treatment led to the de-flocculation of S. obliquus AS-6-11 (data not shown), indicating their different mechanisms of cell selfflocculation. Therefore, we focused on the identification of flocculating proteins in S. obliquus AS-6-11.

Yeast cell flocculation has been widely used in the beer industry and biofuels production as a simple, economic and environmentally friendly way to harvest cells [35, 36]. The interaction of lectin-like receptors with adjacent mannose side chains in cell walls played a vital role in yeast flocculation [37]. In addition to lectin-glycan interaction, glycan-glycan interactions also act a pivotal part in cell-cell adhesion, and the flocculation mechanism contributes to the self-interaction of Flo proteins in the coordination of $\mathrm{Ca}^{2+}[38]$. In our recent studies, mechanisms of cell flocculation in an ethanol-producing bacterium Zymomonas mobilis were also revealed, where cellulose was found to be important for the cell flocculation [39]. Moreover, our previous studies [10, 11] found that cell wall polysaccharides play key roles in microalgal cell self-flocculation. Considering that mannose-specific lectin plays an important role in yeast flocculation [40], the D-mannose binding lectin family gene found in the S. obliquus AS-6-11 genome may be related to cell flocculation. However, we did not find the transcription of this gene in the transcriptome data of S. obliquus AS-611. In the water surface-floating microalga Chlorococcum sp. FFG039, one protein in the unique gene family (jacalin-like lectin domain, PF01419) was assumed to be related to biofilm formation with the help of the lectin domain [41]. However, the gene encoding jacalin-like lectin domain protein was not found in the $S$. obliquus AS-6-11 genome, suggesting the different mechanisms of microalgal flocculation.

GPI-anchored proteins are widespread in eukaryotes for anchoring proteins to the extracellular surface of the plasma membrane, and are involved in multiple cellular functions [42]. GPI-anchored CWP Flo1p in S. cerevisiae is the main flocculation protein, and the GPI-anchor is necessary for Flo1p to attach to the cell wall [27]. However, the GPI-anchored CWPs in microalgae have not been analyzed. Therefore, the genome-scale analysis of GPI-anchored CWPs is of great importance. In the genome of the model plant Arabidopsis thaliana, 210 GPIanchored proteins were identified, and most of these proteins were involved in the primary modification for targeting specific proteins to the cell surface for extracellular matrix remodeling and signaling [43]. According to the GPI-anchor studies of S. cerevisiae and Arabidopsis, the identified cell wall proteins with GPI-anchor of $S$. obliquus AS-6-11 may be related to the attachment of proteins to the cell wall, and the potential flocculation proteins may be members among them. 
Fasciclin 1 (FAS1) domain is an ancient motif in extracellular proteins widely exists in all kingdoms of life, and FAS1 proteins mediated the interactions between the cell surface and cell exterior [44]. FAS1 domain protein of $V$. carteri that is homology to Drosophila fasciclin I was identified as the cell adhesion protein [45], and it also caused unicells of $C$. reinhardtii to flocculate [46]. Therefore, the four proteins identified in this study (Fig. 6a), which are homologous to fasciclin domaincontaining proteins of Synechocystis, D. melanogaster and Galdieria sulphuraria or hypothetical protein of $M$. neglectum and $C$. variabilis, are the most likely flocculation proteins. Although we have made great efforts to investigate the potential flocculating gene function by gene disruption, the genetic transformation method of $S$. obliquus AS-6-11 was not successful. Alternatively, the protein-encoding genes can also be tested in various microalgal species, which will be focused in future studies. It needs to point out that in addition to the function of cell adhesion and/or flocculation, the fasciclin domain proteins in microalgae also take parts in stress response and cell wall formation. The gene encoding one fasciclin domain protein (carotenoprotein) in microalga Ki-4 was overexpressed under salt, dehydration and high light stresses, showing its function in protecting cells against photooxidative stresses [47]. In addition, the fasciclinlike arabinogalactan protein family in higher plant Eucalyptus grandis took parts in the growth and properties of the secondary cell wall [48]. To the best of our knowledge, this is the first report on the analysis of fascilin domain proteins in microalgae. It will be interesting to further explore the functions of this category of proteins. The in-depth analysis of S. obliquus AS-6-11 genome can also provide a basis for functional genomic studies of other microalgae.

\section{Conclusions}

We present here the genome sequencing, annotation, and analysis of the self-flocculating microalga S. obliquus AS-6-11. Comparative genomic analysis between S. obliquus AS-6-11 and the other microalgae reveals its strain specificities, evolutionary status as well as metabolic characteristics. Through the analysis of the protein family, the GPI-anchored CWPs and fasciclin domain proteins were identified for the first time in microalgae, and four GPI-anchored CWPs with fasciclin domain are the most potential flocculation proteins for further studies. Taken together, the draft genome of S. obliquus AS-6-11 will provide a reliable reference for the microalgae genome studies, increasing the understanding of microalgal self-flocculation mechanisms for promoting the microalgal harvest, and benefit efficiency biorefinery using microalgae.

\section{Methods}

Microalgal strain and culture conditions

The self-flocculating S. obliquus AS-6-11 was isolated from the freshwater pond in the campus of National Cheng Kung University $\left(22^{\circ} 99^{\prime} 74.29^{\prime \prime}\right.$, 120 $22^{\prime} 22.30^{\prime \prime}$

E) in southern Taiwan, and was preserved at National Cheng Kung University. Cells were cultured at $25^{\circ} \mathrm{C}$ in BG11 medium with continuous illumination of $75 \mu \mathrm{mol}$ $\mathrm{m}^{2} \mathrm{~s}^{-1}$ and continuous air aeration.

\section{Morphological observation}

The cell shape and surface morphology of $S$. obliquus AS-6-11 cells were observed by scanning electron microscope (SEM, Hitachi S-3400 N II). For SEM, cells during the exponential growth phase were harvested and fixed in $2.5 \%$ glutaraldehyde solution overnight. After that, the samples were washed two times using PBS buffer (10 $\mathrm{mM}, \mathrm{pH} 7.4)$, dehydrated in different concentrations of ethanol solutions, and then referred to the method of Salim et al. [49].

\section{Genome DNA preparation and quality assessment}

Two hundred milliliter cells at the exponential growth phase (Day 6) were harvested. The genome DNA of $S$. obliquus AS-6-11 was extracted by EZ-10 Spin Column Plant Genomic DNA Purification Kit (NO. B518261, Sangon Biotech (Shanghai) Co., Ltd.). The DNA quality was monitored and controlled by Nanodrop (Thermo Scientific NanoDrop 2000) and DNA gel electrophoresis.

\section{Genome sequencing and assembly}

The obtained high-quality DNA was sequenced using the PacBio RS II System. The size of DNA libraries was 10-20 kb and 10 SMRT cells were sequenced. Filtered Pacbio subreads were de novo assembled by software MECAT [29] and SMRT Portal with recommending parameters, respectively. Genome assembly quality using MECAT was further assessed by BUSCO (3.0.2) [50]. The following analyses were based on the MECAT assembly result.

\section{Genome annotation and comparative transcriptome analysis}

MAKER2 training and annotation pipeline [51] with AUGUST [52] and SNAP [53] was used for genome structural annotation of S. obliquus AS-6-11 according to the $C$. reinhardtii training set and S. obliquus AS-6-11 transcriptome data. The transcriptome sequencing was performed by Illumina Hiseq platform. Functional annotation was performed by BLASTp (2.7.1+) [54] according to NR (https://ftp.ncbi.nlm.nih.gov/blast/db/FASTA/) and Swiss-Prot protein (https://ftp.ncbi.nlm.nih.gov/ blast/db/) databases. GO (http://geneontology.org/docs/ download-ontology/) and KEGG (http://www.genome. 
$\mathrm{jp} / \mathrm{kegg} / \mathrm{ko.html}$ ) annotations were performed according to the analysis method of Tamanna Sharma and Rajinder Singh Chauhan [17]. Gene family analysis was performed by InterProScan 5.36-75.0-64 [55] using the amino acid sequences of $S$. obliquus AS-6-11, C. reinhardtii (NCBI accession number: $\mathrm{ABCN} 00000000.2), C$. variabilis (NCBI accession number: ADIC00000000.1), V. carteri (NCBI accession number: ACJH00000000.1) and M. conductrix (NCBI accession number: LHPF00000000.2). In addition, the orthologous gene clusters between these microalgal genomes were compared using OrthoVenn2 (https://orthovenn2.bioinfotoolkits.net/) [25].

For transcriptome analysis, S. obliquus AS-6-11 and $S$. obliquus FSP-3 cells grown for $48 \mathrm{~h}$ under the same condition were harvested at $6000 \mathrm{rpm}$ for $5 \mathrm{~min}$, and then washed three times with the sterilized water. The washed cells were stored at $-80^{\circ} \mathrm{C}$ immediately and send to Novogene Co., Ltd. for initial sequencing and analysis.

\section{Prediction of GPI-anchored cell wall proteins}

GPI-anchored CWPs in S. obliquus AS-6-11 were predicted by the GPI-anchored protein predictor developed by the National Science and technology development agency of Thailand [56]. The top 10 of predicted GPIanchored CWPs with signal peptide were further analyzed using compute pI/Mw tools of ExPASy (https:// web.expasy.org/compute_pi/) and SMART (http://smart. embl-heidelberg.de/). Protein subcellular localization sites were estimated by Protein Subcellular Localization Prediction (https://wolfpsort.hgc.jp/).

\section{Analysis of fasciclin domain proteins}

The fasciclin domain family proteins were extracted from protein family annotation files and further analyzed using compute $\mathrm{pI} / \mathrm{Mw}$ tool of ExPASy, SMART, and Protein Subcellular Localization Prediction.

\section{Phylogenetic analysis of fasciclin domain proteins}

A phylogenetic tree of fasciclin domain proteins was constructed using MEGA 7 [57]. The sequence alignment was performed using MUSCLE and the phylogenetic tree was constructed using the Maximum likelihood method with 1000 bootstrap replicates.

\section{Analysis of the conserved motifs of fasciclin domain proteins}

The motifs' analysis of fasciclin domain proteins was performed by the online MEME website (http://memesuite.org/tools/meme) with the default parameters.

\section{Analysis of conserved domains and homologous protein} The analyses of conserved domains and homologous protein were performed using NCBI CD-Search
(https://www.ncbi.nlm.nih.gov/Structure/cdd/wrpsb.cgi) and NCBI-blastp choosing the UniProtKB/Swiss-Prot database (https://blast.ncbi.nlm.nih.gov/Blast.cgi?PROGRAM= blastp\&PAGE_TYPE=BlastSearch\&LINK_LOC=blasthome), respectively.

\section{Supplementary information}

Supplementary information accompanies this paper at https://doi.org/10. 1186/s12864-020-07142-4.

\section{Additional file 1: Table S1. Genomic features of S. obliquus AS-6-11} using MECAT and SMRT Portal. (DOCX $14 \mathrm{~kb}$ )

Additional file 2:. Assessing genome completeness with BUSCO. (TXT 880 bytes)

Additional file 3: Figure S1. The pairwise heatmap of the overlapping cluster numbers between the pair-wise genomes. (DOCX 55 kb)

Additional file 4: Table S2. Analysis of the fasciclin domain proteins in S. obliquus AS-6-11. (DOCX $20 \mathrm{~kb}$ )

Additional file 5: The amino acid sequences of the potential flocculation proteins of S. obliquus AS-6-11. (TXT 2 kb)

Additional file 6: Table S3. Cq value for the potential flocculating genes in S. obliquus AS-6-11 compared to S. obliquus FSP-3. (DOCX 14 kb)

\section{Abbreviations}

BP: biological process; BUSCO: Benchmarking Universal Single-Copy Orthologs; CC: cellular component; chlo: chloroplast; CWPs: cell wall proteins; cysk: cytoskeleton; cyto: cytoplasmic; DGTT1: type 2 diacylglycerol acyltransferase gene; EP: environmental information processing; EPS: extracellular polymeric substances; E.R.: endoplasmic reticulum; extr: secreted; FAS1 domain: four repeated domains in the fasciclin I family of proteins; golg: golgi apparatus; GP: genetic information processing; GPIanchor: glycosylphosphatidylinositol-anchor; ME: metabolism; MF: molecular function; mito: mitochondrial matrix; Mw: molecular weight; NR: nonredundant; nucl: nuclear; pl: isoelectric point; plas: membrane protein; PSY: synthetic phytoene synthase gene; SGS: second-generation sequencing; SP: signaling and cellular processes; vacu: vacuolar

\section{Acknowledgments}

The authors are thankful to Dr. Zhongqu Duan at Shanghai Jiao Tong University for genome assembly and annotation. We also appreciate Dr. Chun Wan and Professor Fantao Kong at the Dalian University of Technology for helpful discussion.

\section{Authors' contributions}

XQZ designed the project. BLC carried out experiments and analyses of the genome. WM predicted the GPI-anchored proteins. XQZ, SHH, JSC and FWB critically reviewed and revised the manuscript. All authors read and approved the final manuscript.

\section{Funding}

Not applicable.

\section{Availability of data and materials}

The genome sequence information of S. obliquus AS-6-11 was submitted to NCBI with the accession number of PRJNA593662. The amino acid sequences of the potential flocculation proteins of S. obliquus AS-6-11 can be found in Additional file 5. The genome sequences of $C$. reinhardtii (NCBI accession number: $A B C N 00000000.2$ ), C. variabilis (NCBI accession number: $\mathrm{ADIC00000000.1),} \mathrm{V.} \mathrm{carteri} \mathrm{(NCBI} \mathrm{accession} \mathrm{number:} \mathrm{ACJH00000000.1)} \mathrm{and} \mathrm{M.}$ conductrix (NCBI accession number: LHPF00000000.2) were downloaded from the related websites: https://www.ncbi.nlm.nih.gov/genome/?term= ABCN00000000.2\%2C, https://www.ncbi.nlm.nih.gov/genome/?term= ADIC00000000.1, https://www.ncbi.nlm.nih.gov/genome/?term= ACJH00000000.1, and https://www.ncbi.nlm.nih.gov/genome/?term= LHPF00000000.2, respectively. 


\section{Ethics approval and consent to participate}

The self-flocculating S. obliquus AS-6-11 was isolated from the freshwater pond on the campus of National Cheng Kung University, Taiwan by researchers at Prof. Jo-Shu Chang's lab, and no permission is required for sample collection to isolate microalgal strains.

\section{Consent for publication}

Not applicable.

\section{Competing interests}

The authors declare that they have no competing interests.

\section{Author details}

'State Key Laboratory of Microbial Metabolism, Joint International Research Laboratory of Metabolic \& Developmental Sciences, School of Life Sciences and Biotechnology, Shanghai Jiao Tong University, Shanghai 200240, China. ${ }^{2}$ Enzyme Technology Laboratory, National Center for Genetic Engineering and Biotechnology, Pathum Thani 12120, Thailand. ${ }^{3}$ State Key Laboratory of Urban Water Resource and Environment, Harbin Institute of Technology, Harbin 150090, China. ${ }^{4}$ Department of Chemical and Materials Engineering, College of Engineering, Tunghai University, Taichung City, Taiwan. ${ }^{5}$ Research Center for Smart Sustainable Circular Economy, Tunghai University, Taichung City, Taiwan. ${ }^{6}$ Department of Chemical Engineering, National Cheng Kung University, Tainan City, Taiwan.

Received: 16 July 2020 Accepted: 11 October 2020

Published online: 27 October 2020

\section{References}

1. Chen J, Li J, Dong W, Zhang X, Tyagi RD, Drogui P, Surampalli RY. The potential of microalgae in biodiesel production. Renew Sust Energ Rev. 2018;90:336-46.

2. Chew KW, Yap JY, Show PL, Suan NH, Juan JC, Ling TC, et al. Microalgae biorefinery: high value products perspectives. Bioresour Technol. 2017;229: 53-62.

3. Georgianna DR, Mayfield SP. Exploiting diversity and synthetic biology for the production of algal biofuels. Nature. 2012;488:329-35.

4. Starkenburg SR, Kwon KJ, Jha RK, McKay C, Jacobs M, Chertkov O, et al. A pangenomic analysis of the Nannochloropsis organellar genomes reveals novel genetic variations in key metabolic genes. BMC Genomics. 2014;15(1): 212.

5. Bagnato C, Prados MB, Franchini GR, Scaglia N, Miranda SE, Beligni MV Analysis of triglyceride synthesis unveils a green algal soluble diacylglycerol acyltransferase and provides clues to potential enzymatic components of the chloroplast pathway. BMC Genomics. 2017;18(1):223.

6. Ogura A, Akizuki Y, Imoda H, Mineta K, Gojobori T, Nagai S. Comparative genome and transcriptome analysis of diatom, Skeletonema costatum, reveals evolution of genes for harmful algal bloom. BMC Genomics. 2018; 19(1):1-12.

7. Chen CY, Yeh KL, Aisyah R, Lee DJ, Chang JS. Cultivation, photobioreactor design and harvesting of microalgae for biodiesel production: a critical review. Bioresour Technol. 2011;102:71-81.

8. Wan C, Alam MA, Zhao XQ, Zhang XY, Guo SL, Ho SH, et al. Current progress and future prospect of microalgal biomass harvest using various flocculation technologies. Bioresour Technol. 2015;184:251-7.

9. Salim S, Bosma R, Vermuë MH, Wijffels RH. Harvesting of microalgae by bioflocculation. J Appl Phycol. 2011;23:849-55.

10. Guo SL, Zhao XQ, Wan C, Huang ZY, Yang YL, Alam AM, et al. Characterization of flocculating agent from the self-flocculating microalga Scenedesmus obliquus AS-6-1 for efficient biomass harvest. Bioresour Technol. 2013;145:285-9.

11. Alam MA, Wan C, Guo SL, Zhao XQ, Huang ZY, Yang YL, et al. Characterization of the flocculating agent from the spontaneously flocculating microalga Chlorella vulgaris JSC-7. J Biosci Bioeng. 2014;118(1): 29-33.

12. Roccuzzo S, Couto N, Karunakaran E, Kapoore RV, Butler TO, Mukherjee J, et al. Metabolic insights into infochemicals induced colony formation and flocculation in Scenedesmus subspicatus unraveled by quantitative proteomics. Front Microbiol. 2020;11:792.
13. Aljuboori AHR, Uemura Y, Thanh NT. Flocculation and mechanism of selfflocculating lipid producer microalga Scenedesmus quadricauda for biomass harvesting. Biomass Bioenergy. 2016;93:38-42.

14. Fayyaz M, Chew KW, Show PL, Ling TC, Ng IS, Chang JS. Genetic engineering of microalgae for enhanced biorefinery capabilities. Biotechnol Adv. 2020;10:107554.

15. Ling Y, Sun LP, Wang SY, Lin CSK, Sun Z, Zhou ZG. Cultivation of oleaginous microalga Scenedesmus obliquus coupled with wastewater treatment for enhanced biomass and lipid production. Biochem Eng J. 2019;148:162-9.

16. Zhang XY, Zhao XQ, Wan C, Chen BL, Bai FW. Efficient biosorption of cadmium by the self-flocculating microalga Scenedesmus obliquus AS-6-1. Algal Res. 2016;16:427-33.

17. Sharma T, Chauhan RS. Comparative transcriptomics reveals molecular components associated with differential lipid accumulation between microalgal sp. Scenedesmus dimorphus and Scenedesmus quadricauda. Algal Res. 2016;19:109-22.

18. Ho SH, Li PJ, Liu CC, Chang JS. Bioprocess development on microalgaebased $\mathrm{CO}_{2}$ fixation and bioethanol production using Scenedesmus obliquus CNW-N. Bioresour Technol. 2013;145:142-9.

19. Rhoads A, Au KF. PacBio sequencing and its applications. Genom Proteom Bioinf. 2015;13(5):278-89.

20. Nelson DR, Chaiboonchoe A, Fu W, Hazzouri KM, Huang Z, Jaiswal A, et al. Potential for heightened sulfur-metabolic capacity in coastal subtropical microalgae. iscience. 2019;11:450-65.

21. Ma C, Ren H, Xing D, Xie G, Ren N, Liu B. Mechanistic understanding towards the effective lipid production of a microalgal mutant strain Scenedesmus sp. Z-4 by the whole genome bioinformation. J Hazard Mater. 2019;375:115-20.

22. Dasgupta CN, Nayaka S, Toppo K, Singh AK, Deshpande U, Mohapatra A Draft genome sequence and detailed characterization of biofuel production by oleaginous microalga Scenedesmus quadricauda LWG002611. Biotechnol Biofuels. 2018;11(1):308.

23. Carreres BM, de Jaeger L, Springer J, Barbosa MJ, Breuer G, van den End EJ, et al. Draft genome sequence of the oleaginous green alga Tetradesmus obliquus UTEX 393. Genome Announc. 2017:5(3):e01449-16.

24. Starkenburg S, Polle J, Hovde B, Daligault H, Davenport K, Huang A, et al. Draft nuclear genome, complete chloroplast genome, and complete mitochondrial genome for the biofuel/bioproduct feedstock species Scenedesmus obliquus strain DOE0152z. Genome Announc. 2017;5(32): e00617.

25. Wang Y, Devin CD, Chen G, Gu YQ. OrthoVenn: a web server for genome wide comparison and annotation of orthologous clusters across multiple species. Nucleic Acids Res. 2015;43(W1):W78-84

26. Bony $\mathrm{M}$, Barre $\mathrm{P}$, Blondin B. Distribution of the flocculation protein, flop, at the cell surface during yeast growth: the availability of flop determines the flocculation level. Yeast. 1998;14(1):25-35.

27. Bony $M$, Thines-Sempoux D, Barre $P$, Blondin B. Localization and cell surface anchoring of the Saccharomyces cerevisiae flocculation protein Flo1p. J Bacteriol. 1997;179(15):4929-36.

28. Lipke PN. What we do not know about fungal cell adhesion molecules. J Fungi. 2018;4(2):59.

29. Xiao $\mathrm{CL}$, Chen $Y$, Xie SQ, Chen KN, Wang Y, Han Y, et al. MECAT: fast mapping, error correction, and de novo assembly for single-molecule sequencing reads. Nat Methods. 2017:14:1072-4.

30. Nedelcu AM, Lee RW, Lemieux C, Gray MW, Burger G. The complete mitochondrial DNA sequence of Scenedesmus obliquus reflects an intermediate stage in the evolution of the green algal mitochondrial genome. Genome Res. 2000;10(6):819-31.

31. Tripathi R, Gupta A, Thakur IS. An integrated approach for phycoremediation of wastewater and sustainable biodiesel production by green microalgae, Scenedesmus sp. ISTGA1. Renew Energ. 2019;135:617-25.

32. Ye S, Gao L, Zhao J, An M, Wu H, Li M. Simultaneous wastewater treatment and lipid production by Scenedesmus sp. HXY2. Bioresour Technol. 2020;302: 122903.

33. Chen CY, Kao AL, Tsai ZC, Chow TJ, Chang HY, Zhao XQ, et al. Expression of type 2 diacylglycerol acyltransferase gene DGTT1 from Chlamydomonas reinhardtii enhances lipid production in Scenedesmus obliquus. Biotechnol J. 2016;11(3):336-44

34. Chen CY, Kao AL, Tsai ZC, Shen YM, Kao PH, Ng IS, et al. Expression of synthetic phytoene synthase gene to enhance $\beta$-carotene production in Scenedesmus sp. CPC2. J Biotechnol. 2017:12(11):1700204. 
35. Zhao XQ, Bai FW. Yeast flocculation: new story in fuel ethanol production. Biotechnol Adv. 2009;27(6):849-56.

36. Cilliers $\mathrm{JJ}$, Harrison STL. Yeast flocculation aids the performance of yeast dewatering using mini-hydrocyclones. Sep Purif Techn. 2019;209:159-63.

37. Nayyar A, Walker G, Wardrop F, Adya AK. Flocculation in industrial strains of Saccharomyces cerevisiae: role of cell wall polysaccharides and lectin-like receptors. J I Brewing. 2017;123(2):211-8.

38. Goossens KVY, lelasi FS, Nookaew I, Stals I, Alonso-Sarduy L, Daenen L, et al. Molecular mechanism of flocculation self-recognition in yeast and its role in mating and survival. Mbio. 2015;6(2):e00427-15.

39. Xia J, Liu CG, Zhao XQ, Yi X, Xia XX, Bai FW. Contribution of cellulose synthesis, formation of fibrils and their entanglement to the self-flocculation of Zymomonas mobilis. Biotechnol Bioeng. 2018;115(11):2714-25.

40. Javadekar VS, Sivaraman H, Sainkar SR, Khan MI. A mannose-binding protein from the cell surface of flocculent Saccharomyces cerevisiae (NCIM 3528): its role in flocculation. Yeast. 2000;16(2):99-110.

41. Maeda Y, Nojima D, Sakurai M, Nomaguchi T, Ichikawa M, Ishizuka Y, et al. Genome analysis and genetic transformation of a water surface-floating microalga Chlorococcum sp. FFG039. Sci Rep-UK. 2019;9(1):1-7.

42. Fankhauser N, Mäser P. Identification of GPI anchor attachment signals by a Kohonen self-organizing map. Bioinformatics. 2005;21(9):1846-52.

43. Borner GHH, Sherrier DJ, Stevens TJ, Arkin IT, Dupree P. Prediction of glycosylphosphatidylinositol-anchored proteins in Arabidopsis. A genomic analysis. Plant Physiol. 2002;129(2):486-99.

44. Georg S. Fascinating fasciclins: a surprisingly widespread family of proteins that mediate interactions between the cell exterior and the cell surface. Int J Mol Sci. 2018;19(6):1628.

45. Huber O, Sumper M. Algal-CAMs: isoforms of a cell adhesion molecule in embryos of the alga Volvox with homology to Drosophila fasciclin I. EMBO J. 1994;13(18):4212-22.

46. Lowder LG, Herbert SK. Heterologous expression of a Volvox cell adhesion molecule causes flocculation in Chlamydomonas reinhardtii. J Appl Phycol. 2015:27(2):721-31.

47. Kawasaki S, Mizuguchi K, Sato M, Kono T, Shimizu H. A novel astaxanthinbinding photooxidative stress-inducible aqueous carotenoprotein from a eukaryotic microalga isolated from asphalt in midsummer. Plant Cell Physiol. 2013;54(7):1027-40

48. MacMillan CP, Taylor L, Bi Y, Southerton SG, Evans R, Spokevicius A. The fasciclin-like arabinogalactan protein family of Eucalyptus grandis contains members that impact wood biology and biomechanics. New Phytol. 2015; 206(4):1314-27.

49. Salim S, Kosterink NR, Wacka NDT, Vermuë MH, Wijfels RH. Mechanism behind autoflocculation of unicellular green microalgae Ettlia texensis. J Biotechnol. 2014:174:34-8.

50. Simão FA, Waterhouse RM, loannidis $P$, Kriventseva EV, Zdobnov EM BUSCO: assessing genome assembly and annotation completeness with single-copy orthologs. Bioinformatics. 2015;31(19):3210-2.

51. Holt C, Yandell M. MAKER2: an annotation pipeline and genome-database management tool for second-generation genome projects. BMC Bioinformatics. 2011:12(1):491.

52. Stanke M, Diekhans M, Baertsch R, Haussler D. Using native and syntenically mapped CDNA alignments to improve de novo gene finding. Bioinformatics. 2008;24(5):637-44

53. Korf I. Gene finding in novel genomes. BMC Bioinformatics. 2004;5(1):59.

54. Altschul SF, Madden TL, Schäffer AA, Zhang J, Zhang Z, Miller W, et al. Gapped BLAST and PSI-BLAST: a new generation of protein database search programs. Nucleic Acids Res. 1997;25(17):3389-402.

55. Philip J, David B, Hsin-Yu C, Matthew F, Weizhong L, Craig MA, et al. InterProScan 5: genome-scale protein function classification. Bioinformatics. 2014;30(9):1236-40.

56. Phienluphon A, Mhuantong W, Boonyapakron K, Deenarn P, Champreda V, Wichadakul D, et al. Identification and evaluation of novel anchoring proteins for cell surface display on Saccharomyces cerevisiae. Appl Microbiol Biot. 2019;103(7):3085-97.

57. Kumar S, Stecher G, Tamura K. MEGA7: molecular evolutionary genetics analysis version 7.0 for bigger datasets. Mol Biol Evol. 2016;33(7):1870-4.

\section{Publisher's Note}

Springer Nature remains neutral with regard to jurisdictional claims in published maps and institutional affiliations.

Ready to submit your research? Choose BMC and benefit from:

- fast, convenient online submission

- thorough peer review by experienced researchers in your field

- rapid publication on acceptance

- support for research data, including large and complex data types

- gold Open Access which fosters wider collaboration and increased citations

- maximum visibility for your research: over $100 \mathrm{M}$ website views per year

At BMC, research is always in progress.

Learn more biomedcentral.com/submissions 